\title{
Influence of Local Raw Materials on The Mechanical Behaviour and Fracture Process of PVA-SHCC
}

\author{
Margareth da Silva Magalhães ${ }^{\mathrm{a}}$, Romildo Dias Toledo Filho ${ }^{\mathrm{b}}$, Eduardo de Moraes Rego Fairbairn \\ ${ }^{a}$ Departamento de Construção Civil e Transportes, Universidade do Estado do Rio de Janeiro - UERJ, \\ Rua São Francisco Xavier 524, Maracanã, CEP 20550-900, Rio de Janeiro, RJ, Brasil

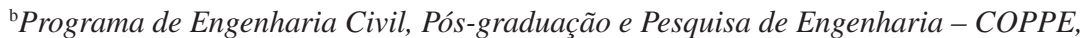 \\ Universidade Federal do Rio de Janeiro - UFRJ, CT, Bloco B, Ilha do Fundão, CP 68506, \\ CEP 21945-970, Rio de Janeiro, RJ, Brasil
}

Received: February 15, 2013; Revised: September 4, 2013

\begin{abstract}
This paper addresses the results of an investigation on the influence of the Brazilian raw materials on the mechanical performance of Strain Hardening Cementitious Composites (SHCC). The mixtures were produced with variations of fly ash/cement and sand/cement proportions and with different maximum sand particle. Mechanical properties were evaluated by direct tension, bending and compression tests. Crack formation under direct tension and bending loads was also investigated. The results indicate that the use of high quantities of fly ash with low quantities of fine sand is the ideal combination to obtain strain hardening composites with tensile strain capacity superior to $3 \%$ using local materials. The increase in the sand content and particle size affects the behavior of the composites and tended to reduce the strain capacity of the specimens by up to $30 \%$. Keeping constant the fly ash/cement and sand/cement rates it was found that the crack density and width measured under direct tension are only affected by the diameter of the sand for tensile strains in the range of $2 \%$. The same general trends were observed for specimens submitted to compressive and bending loads.
\end{abstract}

Keywords: strain hardening cementitious composites (SHCC), local raw materials, ductile behavior, crack density, crack width

\section{Introduction}

Fiber reinforced cementitious composites (FRC) have become the subject of intense studies over the past five decades, and various kinds of fiber reinforced cementitious composites have been developed around the world ${ }^{1}$. Amongst these materials are the strain hardening cementitious composites (SHCC). SHCC is a new class of materials that exhibits extremely ductile behavior under tensile loads often accompanied by a strain hardening response, with a strain capacity of up to 500 times the strain capacity of conventional concrete, rather than the tensionsoftening response of FRC. Its high ductility results from steady state cracking with closely spaced micro cracks (crack width generally below $80 \mu \mathrm{m}$ ). In SHCC, crack openings are controlled by effective fiber bridging to allow crack lengthening and the formation of new cracks in the cementitious matrix, as opposed to significant widening of existing cracks ${ }^{2}$.

Although the concept of SHCC materials is relatively new, its use is gaining acceptance in the construction industry, being successfully used for a number of applications over the last decade. SHCC has been applied to bridge decks, building dampers, surface repair of concrete dams, water channels and retaining walls ${ }^{3}$. According to Toshiyuki et al. ${ }^{3}$, appropriate use of the tensile performance can work out a structural component excellent in both durability and mechanical performance.

*e-mail: margarethsm@yahoo.com.br
The development of SHCC composites is guided by micromechanical principles ${ }^{4-7}$, which provide quantitative links between composite mechanical behavior and the properties of the individual constituents, which are the fiber, matrix and fiber/matrix interface. The design strategy of strain-hardening cement based composites lies in recognizing and tailoring the interaction of those constituents.

Through careful material design, the fiber volume fraction in SHCC remains moderate, typically below $2.5 \%$. Various types of fiber have been successfully used in SHCC such as polyvinyl alcohol (PVA) fiber (commonly called PVA-SHCC), high modulus polyethylene fibers ${ }^{7-9}$ and polypropylene fibers ${ }^{10}$.

According to $\mathrm{Li}^{11}$, the principle behind the design of engineered cementitious composites (ECC), a particular type of SHCC, does not depend on a particular fiber. Fibers with certain properties, however, may meet the criteria for tensile strain hardening at a lower volume fraction. Decisions of which fibres to be used will depend on their natural characteristics, including mechanical characteristics, physical properties and surface characteristics.

Concerning the matrix ingredients, fine silica sand is frequently used in various SHCC compositions to maintain adequate stiffness and volume stability. The silica sand has a maximum grain size of $250 \mu \mathrm{m}$ and a mean size of $110 \mu \mathrm{m}$. Coarse aggregate is not used in the standard SHCC 
mixture because it has shown that the presence of coarse aggregates in a matrix tends to increase the matrix fracture toughness and fiber dispersion, which reduces the margin to develop multiple cracking and achieving strain hardening behavior $^{12,13}$. Compared to conventional concrete mixtures, SHCC mixtures require a higher content of cementitious materials to control the interfacial bond strength. Type I Portland cement and other mineral admixtures, such as fly ash, have been used.

In the literature, it is hypothesized that the increase in matrix toughness, due to an increased amount and size of aggregates, could potentially be offset by the decrease in toughness when a high volume mineral admixture is used in the production of $\mathrm{SHCC}^{14}$.

Several other researchers have also reported the benefits of using fly ash in SHCC mixture ${ }^{14-16}$. These studies have shown that increasing the fly ash content in SHCC mixtures tends to improve the robustness of tensile ductility while retaining a tensile strain of approximately $3 \%$. This is attributed to the fact that the increase in the fly content tends to reduce the fiber/matrix interface chemical bond, while increasing the interface frictional bond, in favor of attaining high tensile strain capacity.

The capability to produce SHCC materials with consistent mechanical properties is crucial for gaining acceptance of this new construction material in various structural applications. SHCC using local raw material have been produced in various countries, including Japan ${ }^{17}$, China $^{18}$, Germany ${ }^{19}$, S. Africa ${ }^{20}$ and Italy ${ }^{21}$, in addition to the USA. In order to spread its use around the world in the construction industry, it is important to study the development and characterization of SHCC with local raw materials.

Therefore, the objective of the current work is to study the mechanical behavior of SHCC composites made with the raw materials available in Brazil. In this research, compressive tests, four point bending tests and direct tension tests were carried out to characterize the behavior of composites. The fracture process, i.e. the crack formation including number, position and width, were also monitored and quantified. The mixtures were produced with variations of fly ash/cement and sand/cement rates and with two types of silica sand (particle maximum sizes of 212 or $1180 \mu \mathrm{m}$ ). All mixes were reinforced with PVA fiber.

\section{Experimental Program}

\subsection{Materials and composite manufacturing}

The raw materials used to produce the mixtures were: Portland cement (C) CPII F-32 composed with $6 \%$ of calcareous filler (Brazilian standard) ${ }^{22}$, with $32 \mathrm{MPa}$ of compressive strength at 28 days; fly ash (FA); two types of silica sand: a fine (FS) one with a maximum diameter of $212 \mu \mathrm{m}$ and a density of $2.60 \mathrm{~g} / \mathrm{cm}^{3}$ and a coarse (CS) one with a maximum diameter of $1180 \mu \mathrm{m}$ and a density of $2.67 \mathrm{~g} / \mathrm{cm}^{3}$; water; polyvinyl alcohol (PVA) fibers; and three types of chemical admixtures (SP) available in the Brazilian market, which were applied to control the rheological properties of fresh matrix: CC583 (manufactured by Cognis) based on melamine with $100 \%$ solid content and density $0.73 \mathrm{~g} / \mathrm{cm}^{3}$, Complast RX 3000 (manufactured by Anchortec) based on melamine with $26 \%$ solid content and density $1.15 \mathrm{~g} / \mathrm{cm}^{3}$ and Glenium 51 admixture (manufactured by MBT Brazil) based on modified polycarboxylic ether with $32.5 \%$ solid content and density $1.20 \mathrm{~g} / \mathrm{cm}^{3}$. The PVA fiber (REC 15) used is produced by Kuraray in Japan with a length of $12 \mathrm{~mm}, 40 \mu \mathrm{m}$ diameter, tensile strength $1600 \mathrm{MPa}$ and Young's modulus 40GPa. The chemical characteristics of the cementitious materials are presented in Table 1 and the particle size distribution of aggregates and cementitious materials are presented in Figure 1.

With the aim of producing a strain hardening cementitious composite with raw materials, easily available in the Brazil, three different variables related to the matrix toughness and interface properties were studied in this experiment. The variables studied were sand content (S/C: 0.6-1.0),

Table 1. Chemical compositions and physical properties of Portland cement and Fly ash.

\begin{tabular}{|c|c|c|}
\hline $\begin{array}{c}\text { Chemical } \\
\text { composition }(\%)\end{array}$ & $\begin{array}{c}\text { Portland } \\
\text { cement }\end{array}$ & Fly ash \\
\hline $\mathrm{Na}_{2} \mathrm{O}$ & 0.331 & 0.26 \\
\hline $\mathrm{MgO}$ & 1.344 & 0.50 \\
\hline $\mathrm{Al}_{2} \mathrm{O}_{3}$ & 3.706 & 28.24 \\
\hline $\mathrm{SiO}_{2}$ & 15.326 & 57.78 \\
\hline $\mathrm{P}_{2} \mathrm{O}_{5}$ & 0.101 & 0.06 \\
\hline $\mathrm{SO}_{3}$ & 3.327 & - \\
\hline $\mathrm{Cl}$ & 0.086 & - \\
\hline $\mathrm{K}_{2} \mathrm{O}$ & 0.189 & 2.54 \\
\hline $\mathrm{CaO}$ & 71.476 & 1.26 \\
\hline $\mathrm{MnO}$ & 0.045 & 0.03 \\
\hline $\mathrm{Fe}_{2} \mathrm{O}_{3}$ & 3.777 & 4.76 \\
\hline $\mathrm{ZnO}$ & 0.034 & - \\
\hline $\mathrm{SrO}$ & 0.257 & - \\
\hline $\mathrm{TiO}_{2}$ & - & 0.95 \\
\hline $\mathrm{BaO}$ & - & $<0.16$ \\
\hline Loss on ignition (\%) & 4.93 & 3.55 \\
\hline Density $\left(\mathrm{g} / \mathrm{cm}^{3}\right)$ & 3.08 & 2.35 \\
\hline
\end{tabular}

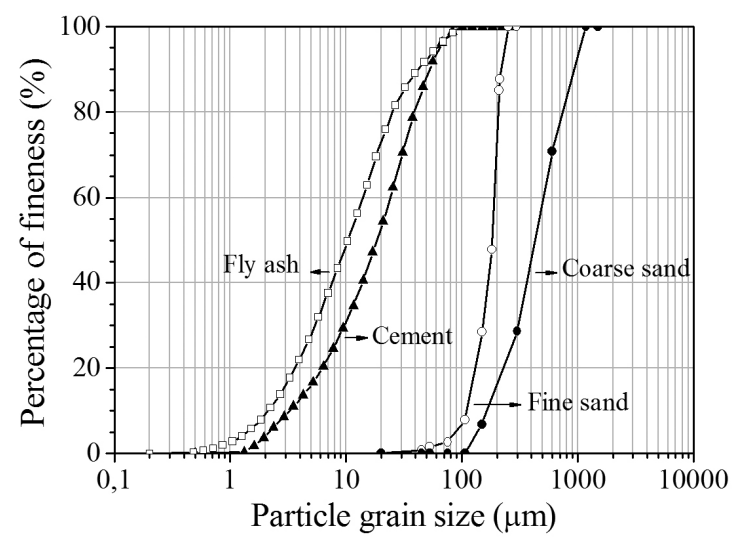

Figure 1. Particle size distribution of cement, fly ash, fine and coarse sand. 
fly ash content (FA/C: 0-1.20) and different particle size distribution of sand (maximum grain size: $212 \mu \mathrm{m}$ and $1180 \mu \mathrm{m})$. In all mixture, the water/cementitious material ratio and chemical admixture type and content were dosed such that all mixtures would have similar fresh properties measured by the flow table test (between 270-300 mm). A slight adjustment in the chemical admixture content and water/cementitious material ratio in each mixture was made to achieve consistent rheological properties for better fiber distribution and workability. The mixture proportions are given in Table 2 .

To produce the mixtures all dry raw materials were mixed for 3 minutes in a mechanical mixer with a 20 liter capacity. Water and superplasticizer were added to form the basic matrix. The mixture was stirred for another 8 minutes to allow appropriate workability of the matrix. In the last step, fibers were added manually to the cementitious matrix and the mixture was stirred for 5 minutes more.

A small flow cone for conventional flow table test was used to quantify the deformability of the fresh mix according to NBR $13276^{[23]}$. Then, the specimens were cast in steel moulds and demolded 24 hours after casting, always covered with damp cloths. The specimens were cured for 28 days in a curing chamber with $100 \%$ relative humidity and $21 \pm 1{ }^{\circ} \mathrm{C}$ of temperature.

\section{Testing Procedure and Methods}

\subsection{Compressive tests}

A compressive strength test was performed on cylindrical specimens of $50 \mathrm{~mm} \times 100 \mathrm{~mm}$ (diameter $\mathrm{x}$ height) in a Shimadzu universal testing machine (UH- FI$1000 \mathrm{KN}$ ) controlled by computer under strain control at a loading rate of $0.2 \% \mathrm{FS} / \mathrm{min}$. The load and corresponding displacement were continuously recorded.

\subsection{Direct tension tests}

Two methods were used in this study for direct tensile testing: setup 01 and setup 02. The setup 01 was used to characterize M01-M04 mixtures. The idea was not to compare the two test setups. They were used in different moments of the study and both were adequate to characterize this type of material. Three rectangular specimens with dimensions of $12.5 \times 40 \times 400 \mathrm{~mm}$ (width $\times$ length $\times$ thickness) were tested using a gauge length of $150 \mathrm{~mm}$ (Figure 2a) in the setup 01. Prior to testing, thin aluminum sheets were glued to both ends of the specimen and the pressure of the hydraulic grips was adjusted to $0.60 \mathrm{MPa}$.

The setup 02 (Figure 2b), proposed by the standard Japanese-JSCE ${ }^{24}$, was used to characterize M05 and M06 mixes. For testing, five dumbbell-shaped specimens with the dimensions of $330 \times 30 \times 30 \mathrm{~mm}$ (length $\times$ width at the narrow section $\times$ thickness) were tested with fixed-fixed boundary conditions in a gauge length of $80 \mathrm{~mm}$. The setup consists of two rigid mechanical grips for fixing the specimen ends, in order to eliminate any misalignment of the sample with the axis of load application.

All direct tension tests were performed using a Shimadzu $100 \mathrm{kN}$ testing machine. The tests were controlled by the cross-head displacement at a rate of $0.1 \mathrm{~mm} / \mathrm{min}$. Two LVDTs (linear variable differential transformers) were used to monitor displacements between two points (gauge length) on the specimen. The LVDTs were mounted on two opposite sides of the specimen with aluminum holders glued to the specimen surface.

The tensile loads and corresponding displacements were continuously recorded by a microcomputer. The stress was obtained by dividing the load by the nominal area of the cross section, while the strain was obtained by dividing the elongation of the specimen by the gauge length.

\subsection{Bending tests}

In order to determine the bending behavior of the studied composites, a Shimadzu Universal testing machine with a capacity of $100 \mathrm{kN}$ was used. The tests were carried out at a crosshead rate of $0.2 \mathrm{~mm} / \mathrm{min}$.

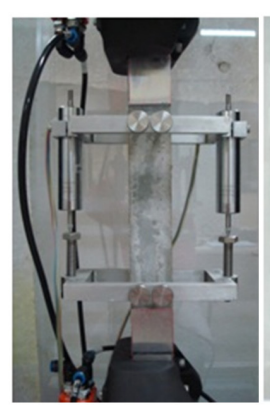

(a)

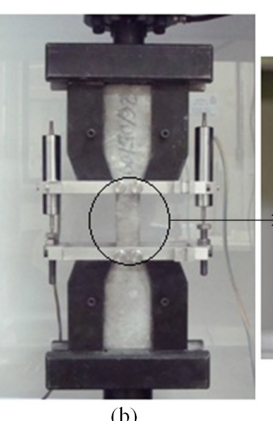

(b)

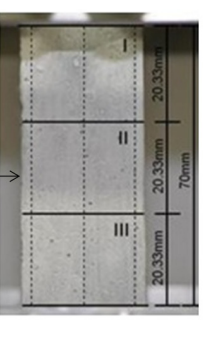

(c)
Figure 2. Direct tension test setups ( $\mathrm{a}$ and $\mathrm{b}$ ) and crack analysis regions of tensile specimen (c).

Table 2. Mixture properties.

\begin{tabular}{|c|c|c|c|c|c|c|c|c|c|c|}
\hline \multirow[t]{2}{*}{ Mix } & \multicolumn{6}{|c|}{ Ingredients, $\mathrm{kg} / \mathrm{m}^{3}$} & \multirow[t]{2}{*}{ FA/C } & \multirow[t]{2}{*}{$\mathrm{S} / \mathrm{C}$} & \multirow{2}{*}{$\begin{array}{c}\text { w/ } \\
(\mathbf{F A}+\mathbf{C})\end{array}$} & \multirow{2}{*}{$\begin{array}{c}\text { Table flow } \\
\text { (mm) }\end{array}$} \\
\hline & $\mathbf{C}$ & FA & $\mathbf{S}$ & Water & SP & PVA & & & & \\
\hline M01 & 848 & - & $848^{\mathrm{FS}}$ & 382 & $17^{\mathrm{a}}$ & 26 & - & 1.0 & 0.45 & 270 \\
\hline M02 & 908 & - & $726^{\mathrm{FS}}$ & 408 & $18^{\mathrm{a}}$ & 26 & - & 0.8 & 0.45 & 275 \\
\hline M03 & 976 & - & $586^{\mathrm{FS}}$ & 440 & $19^{\mathrm{a}}$ & 26 & - & 0.6 & 0.45 & 280 \\
\hline M04 & 852 & 128 & $680^{\mathrm{FS}}$ & 387 & $17^{\mathrm{b}}$ & 26 & 0.15 & 0.8 & 0.38 & 270 \\
\hline M05 & 505 & 605 & $404^{\mathrm{FS}}$ & 404 & $15^{\mathrm{b}}$ & 26 & 1.20 & 0.8 & 0.36 & 290 \\
\hline M06 & 507 & 608 & $406^{\mathrm{CS}}$ & 406 & $3.8^{\mathrm{c}}$ & 26 & 1.20 & 0.8 & 0.36 & 290 \\
\hline
\end{tabular}

C: cement, FA: fly ash; FS: fine sand; CS: coarse sand; SP: admixture (a: CRX300; b: CC583 and c: Glenium51). 
Three samples measuring $400 \times 60 \times 12.5 \mathrm{~mm}$ (length $\times$ width $\times$ thickness) were tested under four point bending loads at a span of $255 \mathrm{~mm}$. Deflections at mid-span were measured using an electrical transducer (LVDT). The loads and corresponding deflections were continuously recorded on a computerized data recording system.

\subsection{Crack patterns characterization method}

Crack patterns were evaluated at regular time intervals during the direct tension and bending tests. A digital Nikon camera, model D90, with 12.3 effective megapixels and AF-S DX Nikkor lens was used to capture images at $60 \mathrm{~s}$ intervals, which were used to evaluated the crack formation (crack width and crack density) during tests. The image of the tension face in the bending tests was taken using a mirror positioned at $45^{\circ}$ to the specimen.

To quantitatively measure crack width, in direct tension tests, an image processing was carried out by the digital processing toolbox of Image J $1.38 \times$ software and correlated with the applied tension strain. The crack width was measured in pixels and the image was calibrated using conventional techniques to convert the size of a pixel to length measures. For the purpose of crack identification and crack width calculation, a set of three lines was selected along the specimen gauge area (Figure 2c). Only the crack was computed that passed through all three lines. The number of cracks was counted as seen on the image at a gauge length of $70 \mathrm{~mm}$ for the tensile specimens (see Figure 2c) and $85 \mathrm{~mm}$ for the bending specimens, located at the central part of the specimen.

The crack density (number of cracks per meter) of each tensile or bending specimen was obtained by dividing the number of cracks by the gauge length. The reported data are the average values from three specimens. The tensile crack density was also calculated for 3 regions along the gauge length of the specimen, identified by Roman numerals, I (top), II (middle) and III (bottom) (see Figure 2c).

\section{Results and Discussion}

\subsection{Compressive behavior of the composites}

The mechanical behavior of the composites was determined at 28 days. Figure 3 shows the typical stressstrain relationship measured from the compressive tests. The mean and the standard deviation (in parenthesis) are summarized in Table 3 . The reported data are the average values from three specimens. Compressive toughness was calculated as the ratio of area under the stress vs. strain curve up to strain of $8000 \mu \varepsilon$ and the equivalent area of the elastoplastic material with the same Young's modulus and compressive strength.

As seen from the results, the compressive strength and Young's modulus of mixtures decreased with decreasing sand content. For example, both the Young's modulus and compressive strength of the mixtures are reduced by approximately $17 \%$ and $15 \%$ respectively when the sand/ cement ratio by weight $(\mathrm{S} / \mathrm{C})$ decreased from 1 (M01) to 0.6 (M03). However, no significant change was observed in strain at peak stress and toughness values by reducing the $\mathrm{S} / \mathrm{C}$ ratio from 1 to 0.6 .

The results also indicated that the replacement of cement by fly ash increased the compressive strength and Young's modulus, while there is no clear trend for the influence of fly ash on strain at the peak load. At FA/C equal to 1.2 (M05), the compressive strength and Young's modulus increased respectively $22 \%$ and $16 \%$ when compared to the result presented by mixture with no addition of fly ash (M02). The toughness, on the other hand, was reduced by approximately $8 \%$. This strength gain may be related to the pozzolanic characteristics of fly ash.

Concerning the influence of sand particle size (M05 and M06 mixture), it was observed that it had a significant influence on the composite compression behavior. The composite produced with fine sand (M05) showed compressive strength, Young's modulus, strain at peak stress and toughness higher than the composite produced with coarse sand (M06). The augment observed were approximately $44 \%, 26 \%, 28 \%$ and $4 \%$ when compared to the respective values presented by composite M06.

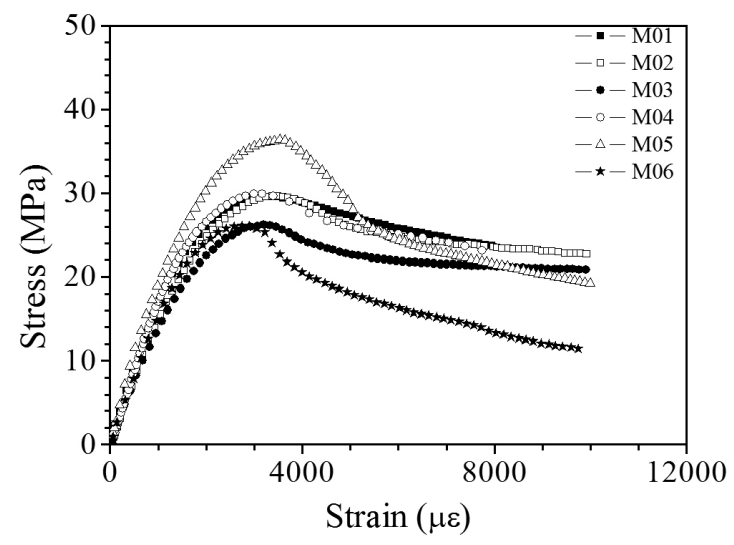

Figure 3. Typical compression stress-strain curves of SHCC mixtures at 28 days.

Table 3. Compressive properties of SHCC mixtures at 28 days (Standard deviation in parenthesis).

\begin{tabular}{ccccc}
\hline Mix & Compressive strength, $\mathbf{f}_{\mathbf{c}}(\mathbf{M P a})$ & Young's modulus, $\mathbf{E}(\mathbf{G P a})$ & Strain at peak stress, $\boldsymbol{\varepsilon}_{\text {pico }}(\mu \varepsilon)$ & Toughness \\
\hline M01 & $30.29(1.67)$ & $18.74(0.53)$ & $3322.03(197.79)$ & $0.87(0.05)$ \\
M02 & $29.58(0.29)$ & $16.41(0.28)$ & $3420.80(49.60)$ & $0.89(0.01)$ \\
M03 & $25.81(1.19)$ & $15.48(0.87)$ & $3305.10(71.76)$ & $0.88(0.04)$ \\
M04 & $30.50(0.87)$ & $18.61(0.28)$ & $3068.37(122.86)$ & $0.87(0.01)$ \\
M05 & $36.27(0.15)$ & $19.00(0.40)$ & $3587.34(6.47)$ & $0.82(0.05)$ \\
M06 & $25.25(0.74)$ & $15.10(0.52)$ & $2803.00(50.00)$ & $0.79(0.05)$ \\
\hline
\end{tabular}




\subsection{Direct tension properties of the composites}

Table 4 summarizes the direct tension tests results with regards to first cracking strength $\left(\sigma_{c c}\right)$, maximum postcracking tensile stress $\left(\sigma_{\mathrm{pc}}\right)$ and strain capacity $\left(\varepsilon_{\mathrm{u}}\right)$. The strain capacity refers to the strain at localization, i.e., when a localized crack opening occurs. In the table, each value represents the average result of three to five specimens. Complete tensile stress-strain curves of the tested specimens are shown in Figure 4.

Table 4. Direct tension properties of SHCC mixtures at 28 days (Standard deviation in parenthesis).

\begin{tabular}{cccc}
\hline Mix & First cracking strength, $\sigma_{\mathrm{cc}}(\mathbf{M P a})$ & Maximum post-cracking tensile stress, $\sigma_{\mathbf{p c}}(\mathbf{M P a})$ & Strain capacity $^{1}, \varepsilon_{\mathbf{u}}(\%)$ \\
\hline M01 & $2.39(0.23)$ & $2.67(0.07)$ & $1.04(0.13)$ \\
M02 & $2.27(0.54)$ & $3.06(0.23)$ & $1.00(0.05)$ \\
M03 & $2.28(0.34)$ & $3.42(0.15)$ & $1.50(0.15)$ \\
M04 & $2.83(0.18)$ & $4.17(0.21)$ & $2.00(0.02)$ \\
M05 & $2.12(0.20)$ & $2.90(0.22)$ & $2.98(0.61)$ \\
M06 & $1.92(0.20)$ & $2.83(0.10)$ & $2.10(0.10)$ \\
\hline
\end{tabular}

${ }^{1}$ The strain capacity refers to the strain at localization.
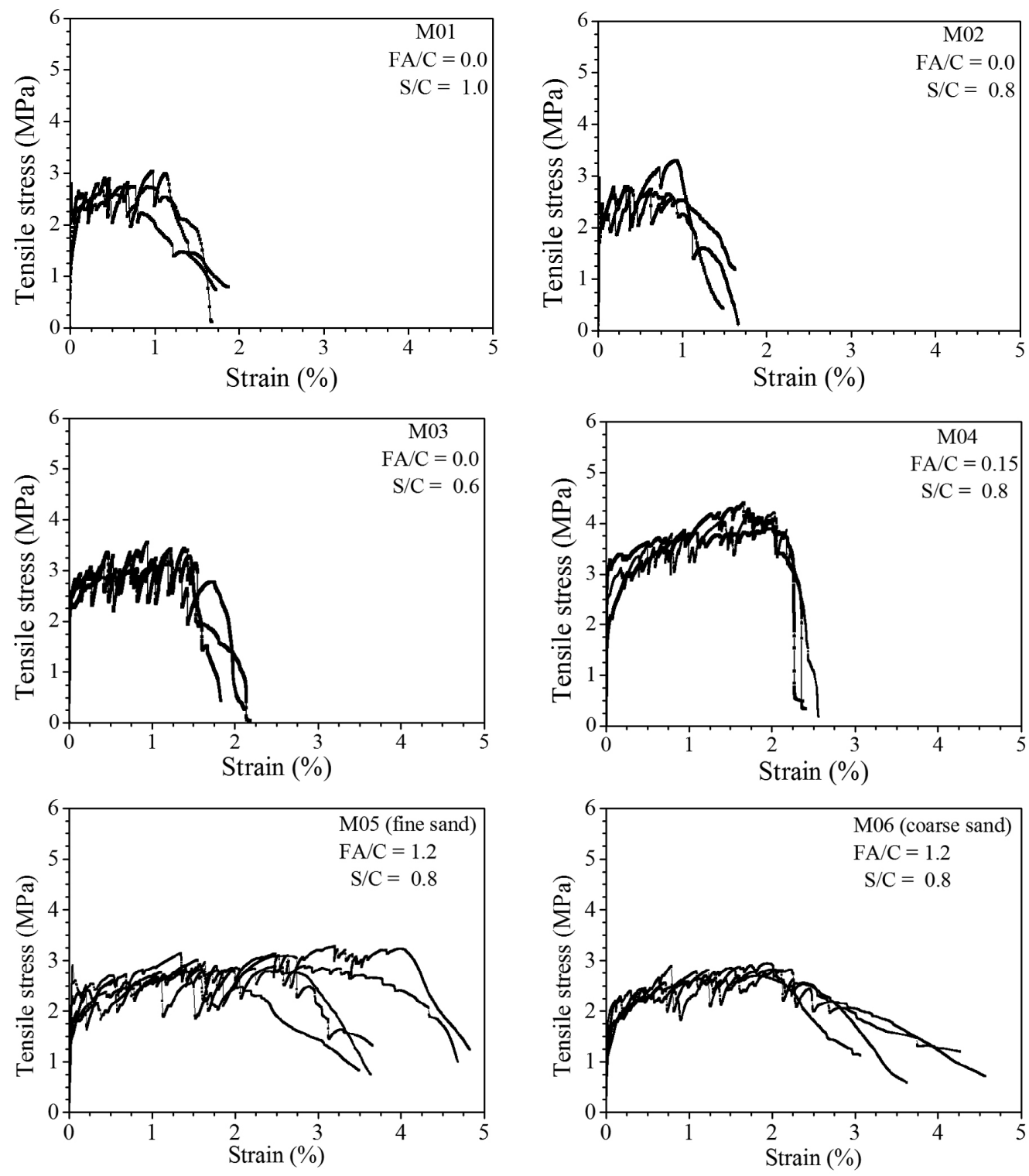

Figure 4. Tensile stress-strain curves of SHCC mixtures at 28 days. 
As seen from the results all experimental mixtures tested showed clearly strain hardening behavior under tensile loads with strain capacity ranging from $1-3 \%$, which are in the range of 100 to 300 times the strain capacity of normal concrete, showing an extremely ductile behavior of composites. This behavior is characterized by three typical zones. Zone I corresponds to the elastic-linear range where both matrix and fiber behave linearly. Due to the low volume fraction of fibers $(2 \%)$ the stiffness of the composite is dominated by matrix properties. The linear zone is terminated by initial crack formation in the matrix (Zone II). After first cracking, its load carrying capacity remains as the cracks are bridged by the longitudinal fibers. Sequentially other cracks also initiate throughout the specimen at approximately regular intervals and begin to propagate across the width of the specimen. This indicates a steady state condition. After the peak stress is reached (Zone III), a localized crack opening occurs in the weak section, which leads to the strain softening behavior and failure of the composite. In this phase, the energy is dissipated in an only crack.

For the set of composites with no fly ash content (M01, M02 and M03 mixtures), it appears that the mixture M03, at $\mathrm{S} / \mathrm{C}$ equal to 0.6 , outperformed the other two. It indicates that the reduction of sand content contributed significantly to the performance of the composite. Augments in strain capacity (44\%) and maximum post-cracking tensile stress (28\%) were observed. This behavior occurs because the presence of sand has an important impact on the micromechanics properties of composites, in terms of both matrix toughness and interfacial properties ${ }^{2}$. A higher amount of aggregates can increase the matrix toughness due to the increase of energy consumption by the tortuous crack propagating path and consequently reduces the strain capacity ${ }^{2}$.

The results also have shown that the use of fly ash in the mixtures provided beneficial effects on the performance of composite. Particularly, for M02, M04 and M05 mixtures, the strain capacities of the composites with an FA/C equal to 1.2 was found to be significantly greater $(100 \%)$ than those with no fly ash content $(\mathrm{FA} / \mathrm{C}=0)$. The results have also shown a slight decrease in first cracking strength (approximately 7\%) and maximum post-cracking tensile stress (approximately 6\%). The increase in the tensile strain with an increased FA content can be attributed to the fact that the increase in the FA content tends to reduce the PVA fiber/matrix interfacial chemical bond and matrix toughness, while increasing the interfacial frictional bond, in favor of attaining high tensile strain capacity ${ }^{15}$.

Concerning the different particle size of silica sand (M05 and M06 mixture), it was observed that an increase of the maximum aggregate size from $212 \mu \mathrm{m}$ to $1180 \mu \mathrm{m}$ had little effect on the first cracking strength and maximum post-cracking tensile stress of specimens. On the other hand, the mixture M06 $(1180 \mu \mathrm{m})$ showed strain capacity $30 \%$ lower than the mixture M05. The negative effects of increasing sand grain size on ductility could be attributed to non-uniform distribution of fibers in the matrix or changes in fiber/matrix interface. According to Sahmaran et al. ${ }^{14}$, the balling of fibers encouraged by coarser sand grain prevents sufficient coating of fibers by the matrix, and thus reduces the fiber/matrix bonding, which is an important factor influencing ductility.

\subsection{Crack pattern of the specimens tested under direct tension loads}

The analysis of the cracking process of the specimens was made for M05 and M06 mixtures. It was based on crack density (number of cracks per meter) and crack width values under direct tension loading. The average crack density was measured for three specimen of each mixture. The crack density evolution with imposed strain for specimens is shown in Figure 5. The figure shows the general increase in the crack density during loading for both composites until strain capacity is reached. In this moment, multiple cracks reach saturated state, i.e, the point of maximum number of cracks per meter. Beyond this point, an increase in crack density was not observed. As no new cracks were forming, it is reasonable to assume that additional imposed strain results in the widening of the existing cracks.

The curves show that the maximum number of cracks per meter is respectively 166 and 137 cracks per meter to M05 and M06 composites. This indicates the greater ability of the composite produced with fine silica sand in crack formation than coarse composite. Such behavior is due to the higher strain capacity of fine composite. However, the curves indicate that the crack density in M06 at the same imposed strain level is almost comparable to one in M05.

Figure 6 shows the crack width development of M05 and M06 mixtures at age of 28 days. The results indicated that average crack width remained under $70 \mu \mathrm{m}$ until the strain capacity is reached for all composites. After this, the average crack width increased until the total rupture of the specimens. It is important to observe that although the coarse composite presented a smaller strain capacity (see Figure 4), both composites presented similar average crack width and crack density up to $2 \%$ strain.

A comparative analysis of crack density of specimens per regions (regions I, II and III) is shown in Table 5 and typical crack patterns of the tensile specimens are shown in Figure 7. It is possible to see the crack formation and propagation with augment of strain level. The results have also shown that, in general, the number of cracks was higher for the central region (II) for all strain levels.

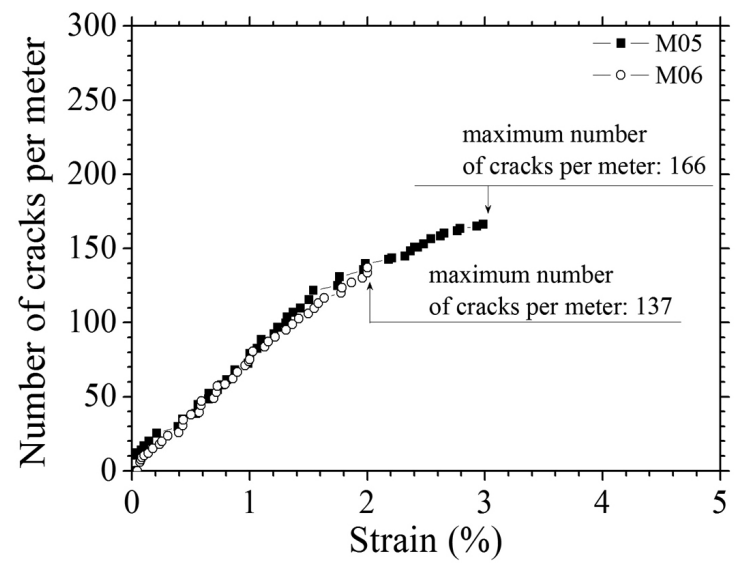

Figure 5. Average crack number per meter - strain curves for M05 and M06 composites under direct tension loads. (Observation area: $30 \mathrm{~mm}$ width $\times 70 \mathrm{~mm}$ length). 

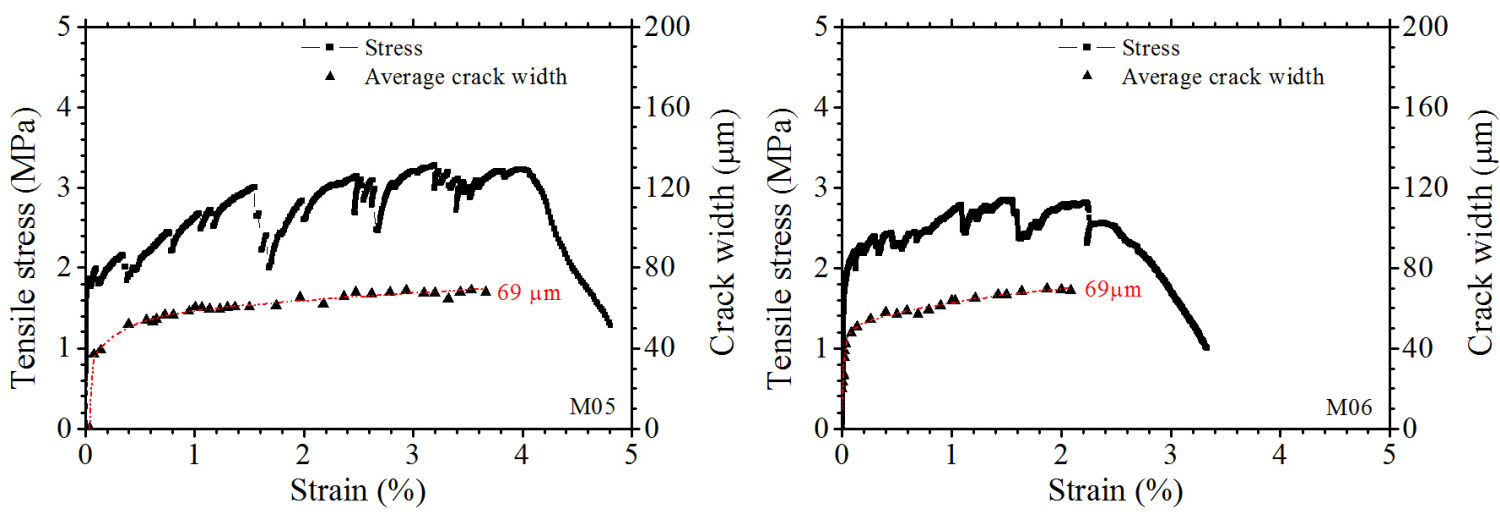

Figure 6. Typical tensile stress and average crack width versus strain curves of M05 and M06 composites.

Table 5. Summary of crack density of the tensile specimens per region (Standard deviation in parenthesis).

\begin{tabular}{ccccccc}
\hline \multirow{2}{*}{,$\%$} & \multicolumn{5}{c}{ M05 } & \multicolumn{3}{c}{ M06 } \\
\cline { 2 - 7 } & I & II & III & I & II & III \\
\hline 0.5 & $42.9(0.0)$ & $42.9(0.0)$ & $42.9(0.0)$ & $42.9(0.0)$ & $57.1(20.2)$ & $42.9(0.0)$ \\
1.0 & $64.3(30.3)$ & $85.7(0.0)$ & $64.3(30.3)$ & $57.1(20.2)$ & $114.3(20.2)$ & $42.9(0.0)$ \\
1.5 & $85.7(0.0)$ & $171.4(0.0)$ & $107.1(30.3)$ & $85.7(0.0)$ & $142.9(20.2)$ & $85.7(0.0)$ \\
2.0 & $85.7(0.0)$ & $192.7(30.3)$ & $128.6(30.3)$ & $128.6(0.0)$ & $185.7(20.2)$ & $114.3(20.2)$ \\
2.5 & $85.7(0.0)$ & $214.3(0.0)$ & $150.0(60.6)$ & & & \\
2.9 & $107.1(30.3)$ & $235.7(30.3)$ & $150.0(30.3)$ & & & \\
\hline
\end{tabular}

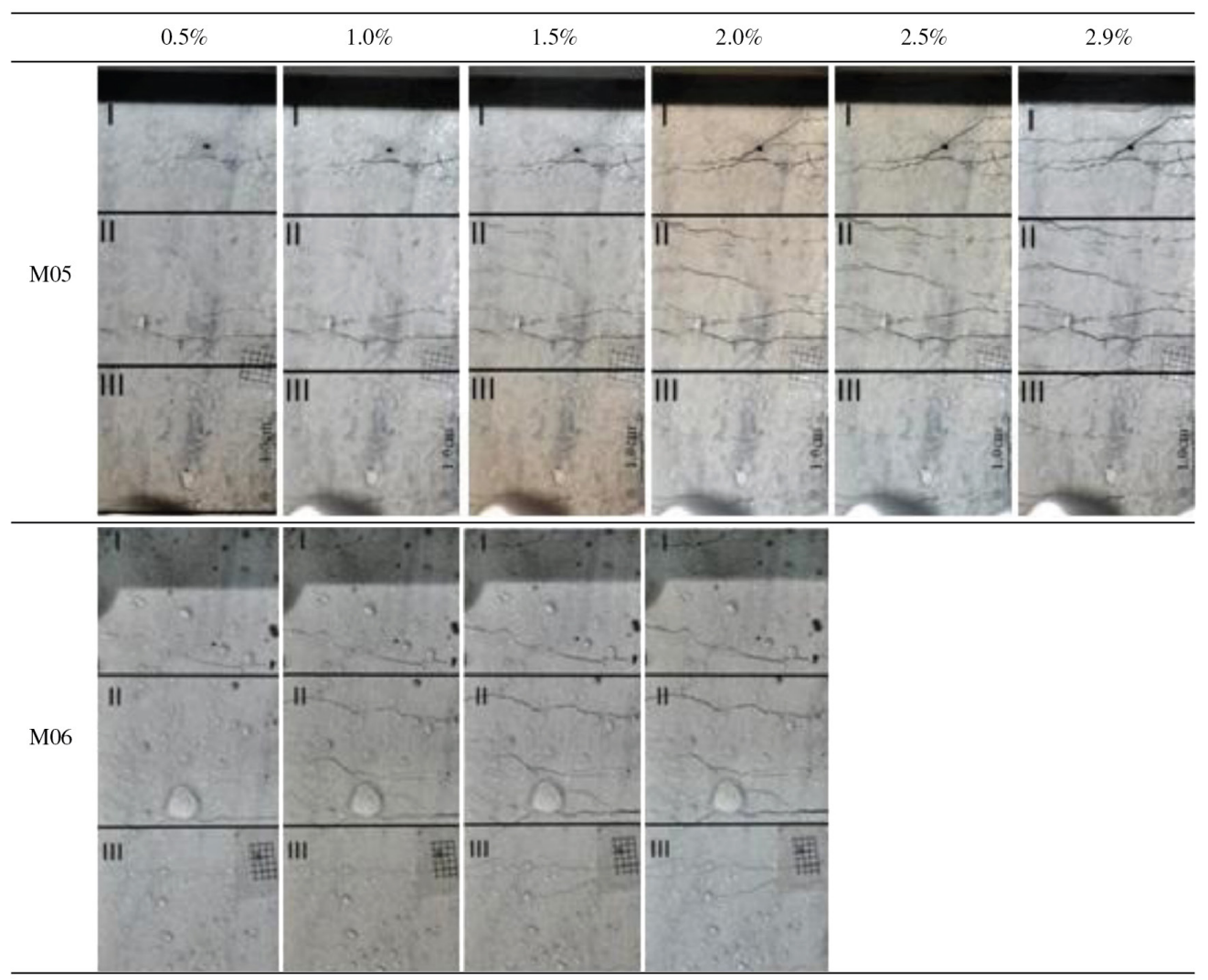

Figure 7. Typical crack pattern of M05 and M06 specimens under direct tension loads. (Observation area: $30 \mathrm{~mm}$ width $\times 70 \mathrm{~mm}$ length). 


\subsection{Bending properties of the composites}

Bending stress - deflection curves obtained for experimental mixtures are shown in Figure 8 and the results in relation to first cracking stress $\left(\sigma_{\mathrm{cr}}\right)$, ultimate bending strength $\left(\sigma_{\mathrm{u}}\right)$ and ultimate deflection $\left(\delta_{\mathrm{u}}\right)$ are summarized
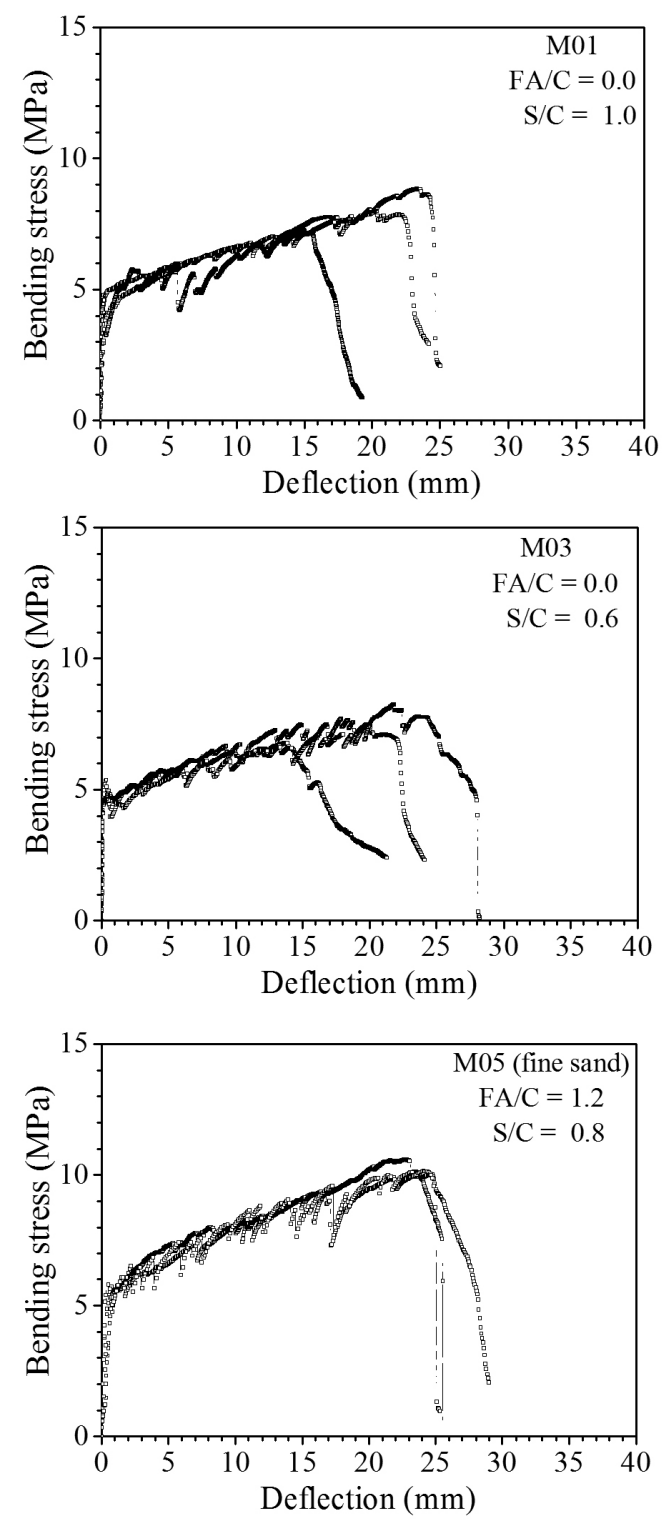

in Table 6. Each result in Table 6 is the average of three specimens. The ultimate deflection refers to the deflection when crack opening localization occurs. As expected, all specimens exhibit apparent multiple cracking patterns accompanying deflection-hardening behavior with ultimate
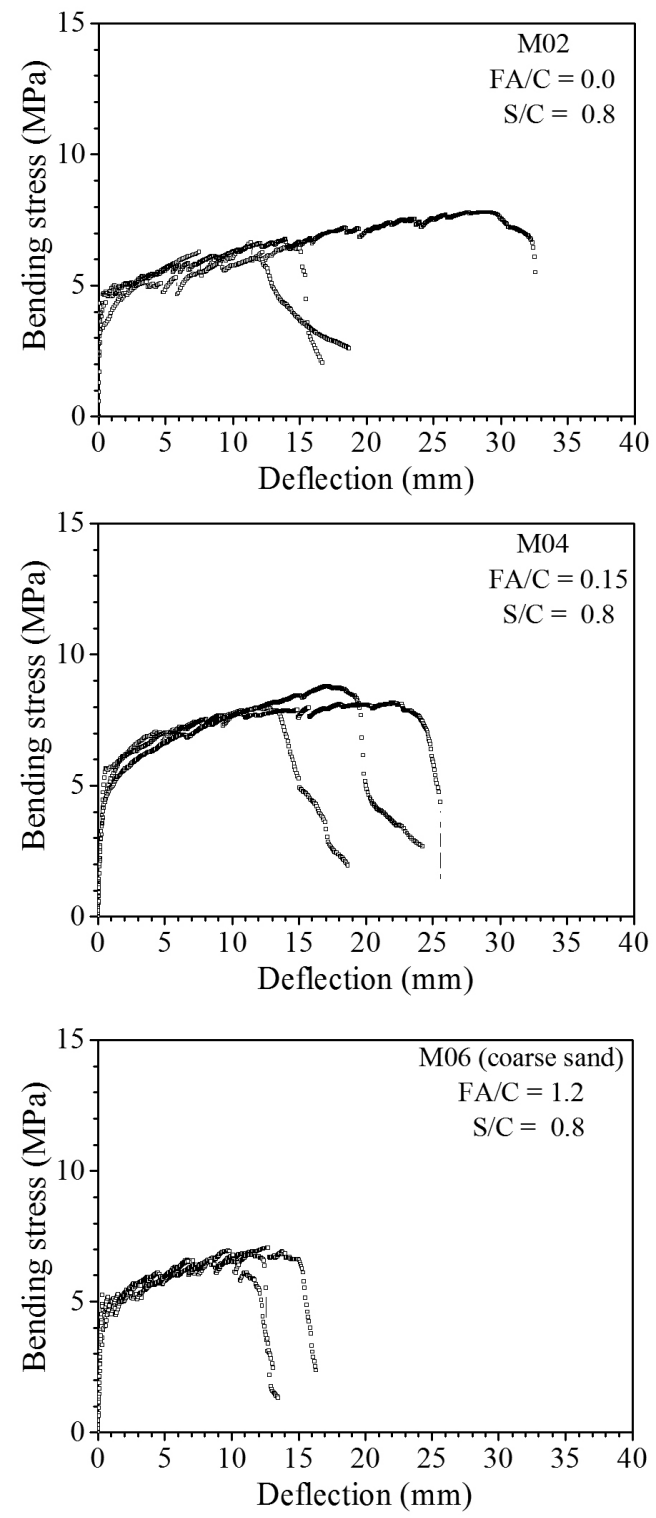

Figure 8. Bending stress-strain curves of SHCC mixtures at 28 days.

Table 6. Bending properties of SHCC mixtures at 28 days (Standard deviation in parenthesis).

\begin{tabular}{cccc}
\hline Mix & First cracking stress $\left(\sigma_{\mathbf{c r}}\right)$ & Ultimate bending strength $\sigma_{\mathbf{u}}(\mathbf{M P a})$ & Ultimate deflection $\boldsymbol{~}_{\mathbf{u}}(\mathbf{m m})$ \\
\hline M01 & $4.69(0.08)$ & $8.03(0.75)$ & $19.6(4.28)$ \\
M02 & $4.54(0.26)$ & $7.38(1.32)$ & $18.51(9.10)$ \\
M03 & $4.36(0.39)$ & $7.28(0.44)$ & $18.77(4.57)$ \\
M04 & $3.92(0.69)$ & $8.20(0.41)$ & $17.86(3.77)$ \\
M05 & $5.61(0.21)$ & $10.25(0.29)$ & $24.20(1.06)$ \\
M06 & $5.14(0.23)$ & $6.88(0.25)$ & $11.61(1.12)$ \\
\hline
\end{tabular}

${ }^{1}$ The ultimate deflection refers to the deflection at localization. 
deflection ranging from 19 to nearly $24 \mathrm{~mm}$. This ductility remains much higher than that in normal concrete and conventional fiber reinforced composite.

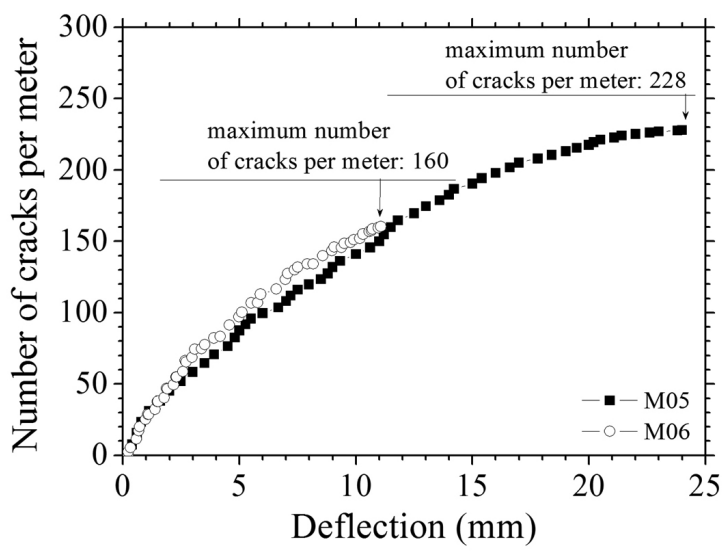

Figure 9. Average crack number per meter - deflection curves for M05 and M06 composites under bending loads. (Observation area: $60 \mathrm{~mm}$ width $\times 85 \mathrm{~mm}$ length).
The results showed that reducing the amount of sand (M01, M02 and M03) tends to reduce the first cracking stress and ultimate bending strength. For the mixture M03, the first cracking stress and ultimate bending strength are respectively $7 \%$ and $9 \%$ lower than for the mixture M01. However, the ultimate deflection did not significantly change. This effect was contradictory with direct tensile tests that have shown a reduction in ductility of the composite with an increase of sand content. Furthermore, it is well known that a higher amount of aggregates generally produces higher fracture energy for plain concrete and, therefore, higher matrix toughness, which is expected to contribute to a reduction in the composite ductility, according to micromechanics theory.

The general trend of first crack stress for tests of the M01, M02 and M03 specimens, which shows a slight increase with the increase of sand content (about of 7.6\%), supports this assertion. However, the tests results have shown no differences in deflection capacity. Thus, this could be attributed to the adverse effect on the uniform dispersion of fiber in the matrix, as indicated by higher standard deviation values presented by deflection capacity in the set of composites with no fly ash content (M01, M02 and M03 mixtures), which affect the ductility of the composite.

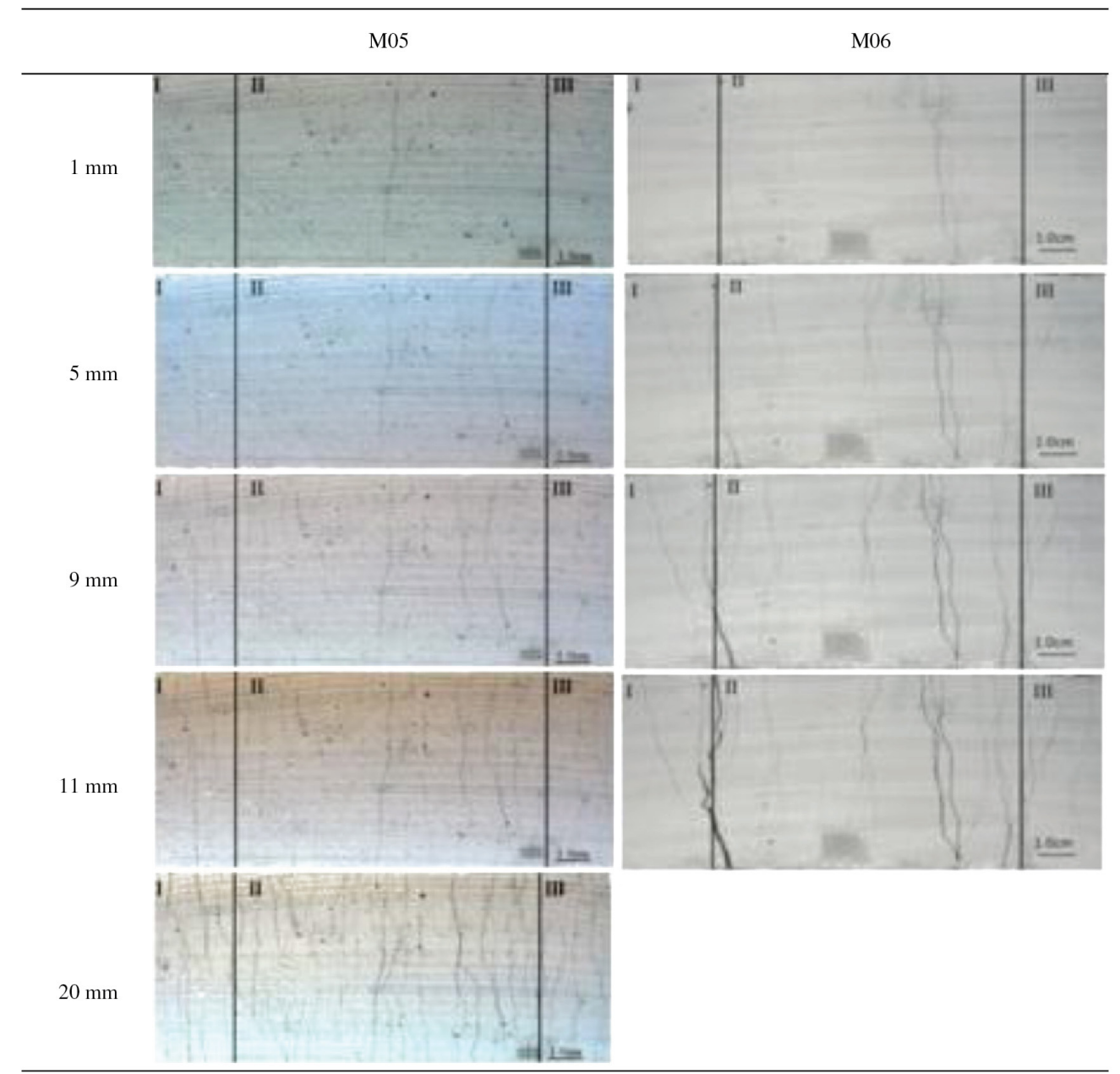

Figure 10. Typical crack pattern of the M05 and M06 specimens under bending loads. 
The results have also shown that the use of fly ash in M04 and M05 mixtures result in a better bending performance in comparison with mixture M02 (with no fly ash content), as well as, resulting in a more robust post-cracking behavior. At FA/C equal to 1.2, ultimate bending strength ultimate deflection and first cracking stress increased, respectively, $40 \%, 31 \%$ and $24 \%$ when compared to the result presented for a mixture with no fly ash addition (M02).

About the different particle size of silica sand, the results have shown that the ultimate deflection and bending strength of the M05 specimens $(212 \mu \mathrm{m})$ are about $40 \%$ and $19 \%$ higher, respectively, than those of the M06 $(1180 \mu \mathrm{m})$ specimens. The results confirm those found in later results of direct tension test. According to Qian and $\mathrm{Li}^{25}$, tensile strain capacity can be derived from deflection capacity by a simplified inverse method, which shows a linear relation between tensile strain capacity and deflection capacity when the material is truly strain-hardening.

\subsection{Crack pattern of the specimens tested under bending load}

Crack density evolution with imposed deflection is illustrated in Figure 9. The average crack density of the bending specimens was measured for three specimens at a gauge length of $85 \mathrm{~mm}$ located at the central part (medium third) of the specimens span. The results have indicated that the crack density, for both composites, increase with the augment of deflection level. The major value of crack density occurred at the end of deflection hardening behavior. After that, the response of the material was deflection softening due to the localization and widening of a major crack. No new cracks appeared at this stage and the crack density remained constant. The results also indicated that although the M06 composite presented a smaller deflection capacity than M05 composite, both composites presented similar crack density for deflections up to $11 \mathrm{~mm}$.

Figure 10 shows the typical crack pattern at the tensile face of M05 and M06 specimens for deflections of 1, 5, 9, 11 and $20 \mathrm{~mm}$. In both specimens, the first crack started inside the midspan at the tensile face. After that, additional microcracks developed and propagated in the midspan of the specimens. It also can be seen that the cracks were widely distributed along the specimens. However, the cracks are spaced in a more regular way in the M05 specimen.

\section{References}

1. Naaman AE. Half a Century of Progress Leading to UltraHigh Performance fiber reinforced concrete: Part 1-Overall Review. In: Proceedings of the 2nd International RILEM Conference; 2011. p. 17-26.

2. Li VC, Wang S and Wu C. Tensile Strain-hardening Behavior of PVA-ECC. ACI Material Journal. 2001; 98(6):483-492.

3. Toshiyuki K, Kabele P, Fukuyama H, Uchida Y, Suwada H and Slowik V. Strain Hardening Cement Composites: Structural Design and Performance. 2013.

4. Kanda T and Li VC. Multiple Cracking Sequence and Saturation in Fiber Reinforced Cementitious Composites. JCI Concrete Research and Technology. 1998; 9(2): 19-33.

\section{Conclusions}

In this work, a study of the influence of the raw material produced in Brazil on mechanical behavior and fracture process of SHCC composites was presented. The following conclusions can be made:

- A series of direct tensile tests demonstrated that it was possible to obtain strain hardening composites with tensile strain capacity superior to $3 \%$ using local raw materials;

- The use of high quantities of fly ash with low quantities of fine sand is the ideal combination to obtain strain hardening composites with higher tensile strain capacity;

- The increase in the content and sand particle size affects the behavior of the composites and tended to reduce the strain capacity of the specimens by up to $30 \%$;

- Keeping constant the fly ash/cement and sand/cement proportions it was found that the crack density and crack width measured under direct tension are only affected by the diameter of the sand for tensile strains levels higher than $2 \%$;

- The average crack width of M05 and M06 specimens remained at approximately $70 \mu \mathrm{m}$ until the strain capacity of the composites is reached. It was also observed that, both composites presented similar crack density up to $2 \%$ and, in general, the crack number was higher for the central region of the specimens than for the extremities;

- Under bending loads, all specimens exhibited a pronounced multiple cracking patterns accompanying deflection-hardening behavior with deflection capacities ranging from 19 to nearly $24 \mathrm{~mm}$;

- The average compressive strength and Young's modulus of the specimens ranged from 25 to $36 \mathrm{MPa}$ and from 15 to $19 \mathrm{GPa}$, respectively. The results also showed that the augment of the sand content, improved the compressive strength and Young's modulus of the specimens, but negatively influenced the tensile ductile behavior of the specimens.

\section{Acknowledgments}

The authors acknowledge the Brazilian Agencies FAPERJ, CAPES and CNPq for the financial support.

5. Li VC and Leung CKY. Steady State and Multiple Cracking of Short Random Fiber Composites. ASCE Journal of Engineering Mechanics. 1992; 118(11): 2246-2264. http:// dx.doi.org/10.1061/(ASCE)0733-9399(1992)118:11(2246)

6. Li VC. Engineered Cementitious Composites-Tailored Composites Through Micromechanical Modeling. In: Banthia N, Bentur A and Mufti A, editors. Fiber Reinforced Concrete: Present and the Future. Canadian Society for Civil Engineering; 1998. p. 64-97.

7. Li VC. From micromechanics to structural engineering - the design of cementitious composites for civil engineering applications. Journal of Structural Mechanics and Earthquake Engineering. 1993; 10(2):37-48. 
8. Li VC and Wang S. Failure mode and structural ductility of GFRP reinforced engineered cementitious composite beams. ACI Material Journal. 99(1):11-21.

9. Kamal A, Kunieda M, Ueda N et al. 2007. Assessment of crack elongation performance in RC beam repaired by UHP-SHCC. In: Proceedings of the Ninth International JSCE Summer Symposium; 2007. Yokohama National University; 2007.

10. Yang EH and Li VC. Strain-hardening fiber-cement optimization and component tailoring by means of a micromechanical model. Journal Construction and Building Material. 2010; 24(2):130139. http://dx.doi.org/10.1016/j.conbuildmat.2007.05.014

11. Li VC. Engineered Cementitious Composites (ECC) - Material, Structural, and Durability Performance. In: Nawy E, editor. Concrete Construction Engineering Handbook. CRC Press; 2008. chapt. 24. http://dx.doi. org/10.1201/9781420007657.ch24

12. Nallthambi P, Karihaloo B and Heaton B. Effect of Specimen and Crack Sizes, Water/Cement Ratio and Coarse Aggregate Texture upon Fracture Toughness of Concrete. Magazine of Concrete Research. 1984; 36(129):227-236. http://dx.doi. org/10.1680/macr.1984.36.129.227

13. Perdikaris PC and Romeo A. Size Effect on Fracture Energy of Concrete and Stability Issues in Three-Point Bending Fracture Toughness Testing. ACI Material Journal. 1995; 92(5):483496.

14. Sahmaran M, Lachemi M, Hossain KMA, Ranade R and Li VC. Influence of Aggregate Type and Size on Ductility and Mechanical Properties of Engineered Cementitious Composites. ACI Materials Journal. 2009; 106(3):308-316.

15. Wang $\mathrm{S}$ and Li VC. Engineered Cementitious Composites with High-volume Fly Ash. ACI Material Journal. 2007; 104(3):233241.

16. Yang EH, Yang Y and Li VC. Use of High Volumes of Fly Ash to Improve ECC Mechanical Properties and Material Greenness. ACI Materials Journal. 2007; 104(6):620-628.
17. Kanda T, Kanakubo T, Nagai S and Maruta M. Technical consideration in producing ECC pre-cast structural elements. In: Proceedings of the International RILEM Workshop on High Performance Fiber Reinforced Cementitious Composites in Structural Applications; 2006. p. 229-242.

18. Zhang Z and Quian S. The feasibility of engineered cementitious composites with local compositions. In: Proceedings of the 2 nd International RILEM Conference; 2011. 2011. p. 323-328.

19. Mechtcherine V and Schulze J. Testing the behavior of strain hardening cementitious composites in tension. In: Proceedings of the International RILEM Workshop on High Performance Fiber Reinforced Cementitious Composites in Structural Applications; 2006. 2006. p. 37-46.

20. Boshoff WP and Van Zijl GPAG. Tensile creep of SHCC. In: Proceedings of the Fifth International RILEM Workshop on High Performance Fiber Reinforced Cement Composites (HPFRCC 5); 2007. 2007. p. 87-96.

21. Ferrara L and Prisco M. The Role of Fiber Orientation on Strain Hardening/Softening FRCC: Continuum Damage Modeling. In: Proceedings of the International RILEM Conference on Strain Hardening Cementitious Composites; 2011. Fairbairn; 2011. p. 79-87.

22. Associação Brasileira de Normas Técnicas - ABNT. NBR 11578 : Cimento Portland Composto. ABNT; 1991. 5 p.

23. Associação Brasileira de Normas Técnicas - ABNT. NBR 13276: Argamassa para Assentamento e Revestimento de Paredes e Tetos - Preparo da mistura e determinação do índice de consistência. ABNT; 2005. 3 p.

24. Japan Society of Civil Engineers - JSCE. Recommendations for Design and Construction of High Performance Fiber Reinforced Cement Composites with Multiple Fine Cracks (HPFRCC). Concrete Engineering Series. 2008; 82.

25. Qian S and Li VC. Simplified Inverse Method for Determining the Tensile Strain Capacity of Strain Hardening Cementitious Composites. Journal of Advanced Concrete Technology. 2007; 5(2):235-246. http://dx.doi.org/10.3151/ jact.5.235 